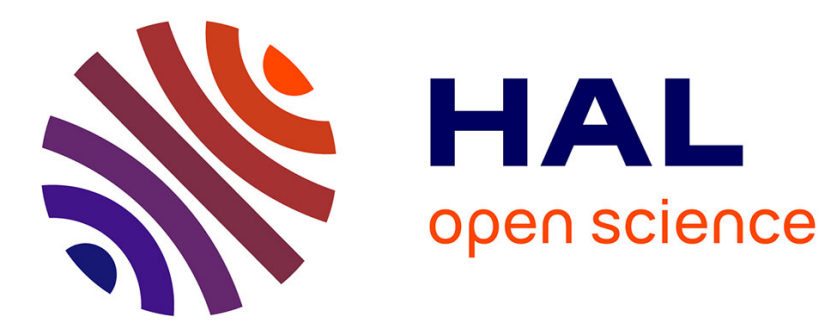

\title{
Rectangular Plates Subjected to Blast Loading: the Comparison Between Experimental Results, Numerical Analysis and Simplified Analytical Approach
}

\author{
K. Cichocki, U. Perego
}

\section{- To cite this version:}

K. Cichocki, U. Perego. Rectangular Plates Subjected to Blast Loading: the Comparison Between Experimental Results, Numerical Analysis and Simplified Analytical Approach. Journal de Physique IV Proceedings, 1997, 07 (C3), pp.C3-761-C3-766. 10.1051/jp4:19973129 • jpa-00255415

HAL Id: jpa-00255415 https://hal.science/jpa-00255415

Submitted on 1 Jan 1997

HAL is a multi-disciplinary open access archive for the deposit and dissemination of scientific research documents, whether they are published or not. The documents may come from teaching and research institutions in France or abroad, or from public or private research centers.
L'archive ouverte pluridisciplinaire HAL, est destinée au dépôt et à la diffusion de documents scientifiques de niveau recherche, publiés ou non, émanant des établissements d'enseignement et de recherche français ou étrangers, des laboratoires publics ou privés. 


\title{
Rectangular Plates Subjected to Blast Loading: the Comparison Between Experimental Results, Numerical Analysis and Simplified Analytical Approach
}

\author{
K. Cichocki and U. Perego*
}

Technical University of Koszalin, ul. Raclawicka 15-17, 75-620 Koszalin, Poland

* Dipartimento di Ingeneria Strutturale, Technical University of Milan, Piazza Leonardo da Vinci 32, 20-133 Milano, Italy

\begin{abstract}
The purpose of the present work was to compare the well-documented results of experiments on steel rectangular plates subjected to blast loading, carried out by Jones, Uran and Tekin [1], with the explicit finite element analysis (ABAQUS/Explicit [2]) and the simplified analytical solution, based on a kinematic approach. This study was undertaken in order to establish the conclusions concerning the possible application of the simplified approach, and evaluate the capacity of material modelling in ABAQUS/Explicit in a case of extremely high velocities of deformation.
\end{abstract}

\begin{abstract}
Résumé. L'objectif du present travail était la comparaison des résultats des expérimentations pour les plaques rectangulaires en acier chargées d'explosion, réalisées par Jones, Uran et Tekin [1] á l'analyse par la méthode des éléments finis (programme ABAQUS/Explicit [2]) de méme qu'á la solution analytique simplifiqe.

Ces recherche étaient entreprises afin d'obtenir les conclusions concernant l'utilisation éventuelle de la jonction simplifiee de méme que de préciser l'efficacité du modéle matériel employé dans le programme ABAQUS/Explicit dans le cas d'une trés grande vitesse de déformation.
\end{abstract}

\section{INTRODUCTION}

Study of large deformation dynamic plastic response of structures is of at most importance in engineering problems, such as these due to explosion and impact loading. Civil applications concern safety assessment of structural components in industrial installations, like nuclear and thermal power plants. which may be impinged by the pressure wave generated by a nearby accidental explosion. Other common applications can be found in offshore, aerospace and automotive industry.

Complexity of these problems increases appreciably when effects due to nonlinear variation of yield stress with strain rate are considered. Because of this the transient response of structures subjected to the loads of such kind must in general be analyzed by numerical methods implemented in computer codes.

These available numerical approaches are generally time consuming, costly and often provide results which agree only qualitatively with the real dynamic response. The results of computer simulation of a dynamic response in a case of impulsive loads are available in literature $[3,4,5]$. The simplified methods are the alternative for a numerical approach, providing a first-hand, inexpensive estimate of a maximum permanent deflection of structures subjected to the uniform impulsive load. Mostly they are limited to the relatively simple structures: beams and plates of a regular shape $[1,6,7,8]$, but they take into account many important features as strain-rate sensitivity, large displacements, and assume the rigid-plastic behaviour for the material, obeying either von Mises or Tresca yielding criterion.

The aim of this work was to compare the results of the numerical analysis, carried out by means of commercial computer code ABAQUS/Explicit V. 5.5, and the results of the simplified analysis by so-called kinematic approach with adequate experimental data available in literature [1].

Special attention was focused on the influence of the rate-dependent formulation according to CowperSymonds model on the final results. Finally, the various discrete models of the problem have been tested and critically compared. 


\section{DESCRIPTION OF EXPERIMENT}

The experiment was made by Jones et al. [1]. The authors presented the results of over 40 tests or rectangular plates, fully clamped around the outer boundary, which were subjected to uniformls distributed initial velocities with an initial energy considerably larger than the maximum elastic strain energy capacity of the corresponding structure.

The target areas of all specimens measured $76.20 \times 128.59 \mathrm{~mm}$. The specimens were made from eithes hot-rolled mild steel or aluminium 6061-T6 and had the average mechanical properties listed in Tables 1 and 2. The thickness was varying from $1.63 \mathrm{~mm}$ to $4.39 \mathrm{~mm}$ for a mild steel specimens, and from $3.1 \mathrm{li}$ $\mathrm{mm}$ to $6.20 \mathrm{~mm}$ for the aluminium ones. The rectangular plate specimen is shown in the Fig. 1.

\begin{tabular}{|c|c|c|}
\hline $\begin{array}{c}\text { Nominal } \\
\text { thickness [mm] }\end{array}$ & $\sigma_{\mathrm{O}}[\mathrm{MPa}]$ & $\sigma_{\mathrm{u}}[\mathrm{MPa}]$ \\
\hline 1.62 & 248 & 326 \\
\hline 2.49 & 233 & 296 \\
\hline 4.39 & 254 & 331 \\
\hline
\end{tabular}

Table 1. Mechanical properties of mild steel $\left(\rho=7723 \mathrm{~kg} / \mathrm{m}^{3}\right)$

\begin{tabular}{|c|c|c|}
\hline $\begin{array}{c}\text { Nominal } \\
\text { thickness }[\mathrm{mm}]\end{array}$ & $\sigma_{\mathrm{o}}[\mathrm{MPa}]$ & $\sigma_{\mathrm{u}}[\mathrm{MPa}]$ \\
\hline 3.10 & 284 & 316 \\
\hline 4.78 & 281 & 313 \\
\hline 6.20 & 286 & - \\
\hline
\end{tabular}

Table 2. Mechanical properties of aluminium $\left(\rho=2735 \mathrm{~kg} / \mathrm{m}^{3}\right)$

\section{NUMERICAL SIMULATION}

Figure 3 shows the geometry of the discretize model that was adopted. Generally the model comprise a $1 / 4$ part of the plate with adequate boundary conditions. Load produced by an explosion is modelled as an uniform initial velocity of the plate.

As a material model, the classical von Mises yielding criterion with kinematic hardening and associative flow rule has been adopted. The rate sensitivity is captured in a simple way by the Cowper-Symonds model. This model, in uniaxial and also in Mises equivalent variables, reads:

$$
\frac{\sigma_{y}}{\sigma_{0}}=1+\left(\frac{\dot{\varepsilon}^{v p}}{D}\right)^{\frac{1}{p}}
$$

where $\sigma_{0}$ denotes the quasi-static yield limit, $\varepsilon^{\mathrm{vp}}$ the inelastic (viscoplastic) strain, and $\mathrm{D}, \mathrm{p}$ are two material parameters. For mild steel the standard values are: $D=40.4 \mathrm{~s}^{-1}, \mathrm{p}=5$, for aluminium $\mathrm{D}=6500 \mathrm{~s}^{-1}, \mathrm{p}=4$ [9].

To examine the importance of rate-dependent material behaviour, the entire analysis has been madetwice. with and without rate-dependence. No failure assumption was taken into account, because only light damage of the plates has been noted upon completion of the experiments.

Two types of finite elements were considered: a 4 node quadrilateral shell element (with 1 point of Gauss on the surface, and 5 points of integration across the thickness), and a 4-node quadrilateral membrane element (with 1 point of Gauss). This was to evaluate the importance of bending behaviour for the total dynamic response of the structure, in a case of the large plastic deformation.

The finite element code ABAQUS/Explicit V.5.5 was applied. All the calculation were made on the workstation Silicon Graphics INDY.

\section{SIMPLIFIED METHOD}

A kinematic approach is proposed here, where a deflected configuration with a constant shape and varying amplitude is sought. Following the previous work by Nurick et al. [6] the flexural resistance of the plate was omitted. As shown by Jones [10], in a clamped rigid - plastic plate the bending resistance is vanishing as the transverse deflection is approaching the depth of the beam section, due to the interaction betwent 
bending moments and axial forces in a sectional plastic yield condition. In the subsequent deformation the plate behaves as a plastic membrane.

We pursue a kinematic approach using cosinusoidal shape functions in both directions. The underlying assumptions are summarized below:

a) rigid - plastic behaviour without hardening obeying von Mises criterion;

b) negligible in-plane displacements on the plate mid-plane;

c) strain-rate sensitivity according to Perzyna's model;

d) moderately large displacements - von Karman plate theory can be applied;

e) transverse deflection expressed in a modal form;

f) negligible bending resistance of the plate;

g) uniformly distributed impulsive loading.

The dissipation rate per unit surface can be easily expressed in each point of the plate, as:

$$
\mathrm{d}=\mathrm{N}_{\mathrm{I}} \dot{\eta}_{\mathrm{I}}+\mathrm{N}_{\mathrm{II}} \dot{\eta}_{\mathrm{II}}=\frac{2}{\sqrt{3}} \mathrm{~N}_{0} \dot{\eta}_{\mathrm{I}}
$$

where: $N_{I}, N_{I I}$ are the principal membrane forces, $N_{0}=\sigma_{0} \mathrm{H}$ is the membrane force at the elastic limit;

$$
\dot{\eta}_{\mathrm{I}}=\frac{2 \mathrm{~N}_{\mathrm{I}}-\mathrm{N}_{\mathrm{II}}}{2 \mathrm{~N}_{0}} \dot{\lambda}, \dot{\eta}_{\mathrm{II}}=\frac{2 \mathrm{~N}_{\mathrm{II}}-\mathrm{N}_{\mathrm{I}}}{2 \mathrm{~N}_{0}} \dot{\lambda}
$$

$\dot{\lambda}$ is a scalar plastic multiplier.

Reference is made to rectangular plates with sides $L$ and $B(\beta=L / B)$. The plate deflection is expressed as a product of the function $W$ of time and the shape function $\phi$ which vanishes at the plate edges.

$$
\tilde{w}(x, y ; t)=W(t) \phi(x, y)
$$

The approximated expression of the dissipation density reads:

$$
\tilde{\mathrm{d}}=\frac{2}{\sqrt{3}} \mathrm{~N}_{0} \tilde{\dot{\eta}}=\frac{2}{\sqrt{3}} \mathrm{~N}_{0} \mathrm{~W}(\mathrm{t}) \dot{\mathrm{W}}(\mathrm{t})\left[\phi_{, \mathrm{x}}^{2}(\mathrm{x}, \mathrm{y})+\phi_{, y}^{2}(\mathrm{x}, \mathrm{y})\right]
$$

The energy dissipated throughout the deformation process is given by:

$$
\tilde{D}=\int_{0}^{t f}\left[\iint_{0}^{L B} d(x, y ; t) d x d y\right] d t=\frac{1}{\sqrt{3}} N_{0} W_{f}^{2} \iint_{0}^{L}\left[\phi_{0}^{L}\left[\phi_{, x}^{2}+\phi_{, y}^{2}\right] d x d y\right.
$$

where: $\mathrm{t}_{\mathrm{f}}$ - final time (when velocity $\dot{\mathrm{W}}\left(\mathrm{t}_{\mathrm{f}}\right)=0$ ), $\mathrm{W}_{\mathrm{f}}=\mathrm{W}\left(\mathrm{t}_{\mathrm{f}}\right)$.

The final deflection can be easily computed in a closed form by imposing that the total dissipation equals the initial kinetic energy $\mathrm{K}_{\mathrm{O}}$ imparted to the plate by the external impulse. However, a more accurate estimate is obtained by assuming $\tilde{D}=K_{0}^{*}=64 K_{0} / \Pi^{4}$, where $K_{0}^{*}$ is the effective initial kinetic energy obtained according to the optimization procedure proposed in [11]. If the cosine functions are used in both directions for the transverse deflection:

$$
\phi(x, y)=\cos \frac{\Pi x}{L} \cos \frac{\Pi y}{B}
$$

the closed form estimate of the final deflection is as follows:

$$
\mathrm{W}_{\mathrm{f}}=\sqrt{\frac{4 \sqrt{3}}{\Pi^{2}} \frac{\beta}{1+\beta} \frac{\mathrm{K}_{0}^{*}}{\mathrm{~N}_{\mathrm{o}}}}
$$

Assuming the viscoplastic model of Perzyna, the following equation was obtained:

$$
\mathrm{N}_{\mathrm{I}}=\frac{2}{\sqrt{3}} \mathrm{~N}_{0}\left[1+\left(\frac{2}{\sqrt{3 \dot{\varepsilon}_{0}}} \dot{\eta}_{\mathrm{I}}\right)^{\frac{1}{\mathrm{n}}}\right]
$$

where $\dot{\varepsilon}_{0}, \mathrm{n}$ are material parameters.

Upon adequate substitution for $\tilde{\dot{\eta}}_{\mathrm{I}}$, an expression is obtained for $\tilde{\mathrm{d}}$ which is not explicitly integrable in time. At this stage, starting from the assumed displacement field, a possible solution is to construct the one d.o.f. equation of motion and to integrate it by a step-by-step numerical technique. 


\section{ANALYSIS OF RESULTS AND FINAL REMARKS}

In the Figure 2 the results obtained by the simplified method are compared with experimental data expressed as a function of so-called load factor $\Phi$, defined as follows:

$$
\Phi=\frac{B}{2 H} \sqrt{\frac{\beta \rho}{\sigma_{0}}} \dot{w}_{0}
$$

where $\rho$ is the material density, and $\dot{w}_{0}$ is the uniformly distributed assigned initial velocity. As one can. see, the experimental results agree enough with analytical simplified rigid-viscoplastic estimation.

A small part of numerical results obtained with the use of ABAQUS/Explicit code is presented in Figs 4-8. First, the dissipated energies of plastic deformation for various options of discrete modelling are shown in the Fig. 4. As it was expected, there is a great difference between results obtained with, and without assumption of rate-dependent sensitivity of the material constitutive model. This assumption has no influence on the time $t_{\mathrm{f}}$ (the end of plastic dissipation), which is almost equal in all cases.

Figures 5 and 6 show the final distribution of plastic equivalent strain $\varepsilon_{\mathrm{eq}}^{\mathrm{p}}(\mathrm{t})$ on the surfaces of shell and membrane structure. For the shell, the values in the midsurface (third point of integration across the thickness) are shown.

In the Figs 7 and 8 the permanent profiles of deformed steel and aluminium specimens are compared with results of numerical analyses with various options of modelling. The assumed values of Cowper-Symonds parameters give the results close enough the experimental data for the steel specimens. but the the results for aluminium differ much more from the experimental ones.

In conclusions we can state that both simplified and numerical analyses may be applied to solve the problems concerning the impact loadnings of the structures modelled as a simple quadrilateral plate

\section{ACKNOWLEDGMENTS}

The research carried out by K.Cichocki is under the research grant 7 T07E 06008 of the Commitee for Scientific Research (KBN). This support is gratefully acknowledged.

\section{REFERENCES}

[1] N.Jones, T.O.Uran and S.A.Tekin, The dynamic plastic behavior of fully clamped rectangular plates. Int. J. Solids Structures, Vol. 6 (1970), pp. 1499 - 1512.

[2] ABAQUS/Explicit User's Manual Ver. 5.5, HKS, Pawtucket USA, 1995.

[3] K.Cichocki, G.Maier and U.Perego, Analysis of damages due to underwater explosions on a hybrid structure, Int. Journ. Engng. Analys. Des., Vol. 1 (1994), pp. 341 - 361.

[4] K.Cichocki, G.Maier and U.Perego, On numerical simulations of explosions on sealines, Proceedings: of the 9th DYMAT Technical Conference, Munich 1995.

[5] M.N.Islam, K.Kormi and S.T.S. Al-Hassani, Dynamic response of a thin walled cylinder to side pressure pulse, Eng. Struct., Vol. 14 (1992), pp. 395 - 412.

[6] G.N.Nurick, H.T.Pearce and J.B.Martin, "The deformation of thin plates subjected to impulsiv? loading", Inelastic Behaviour of pates and Shells - IUTAM Symposium (Edited by L.Bevilacqua. R.Feijoo and R.Valid). Springer - Verlag, Rio de Janeiro 1986.

[7] M.D.Olson, G.N.Nurick and J.R.Fagnan, Deformation and rupture of blast loaded square plates Predictions and experiments, Int. J. Impact Engng, Vol. 13 (1993), pp. 279 - 291.

[8] G.N.Nurick, G.C.Shave, The deformation and tearing of thin square plates subjected to impulsive loads - An experimental study, Int. J. Impact Engng., Vol. 18 (1996), pp. 99 - 116.

[9] D.C.Stouffer, L.T.Dame, Inelastic deformation of metals, Wiley, 1996.

[10]N.Jones, A theoretical study of the dynamic plastic behaviour of beams and plates with finite deflections, Int. J. Solids Struct., Vol. 7 (1970), pp. 1499 - 1512.

$111]$ J.B.Martin, P.S.Symonds, Mode approximation to impulsively loaded rigid-plastic structures. ACE J. Engng. Mech.. Vol. 92 (1966), pp. 43-66. 


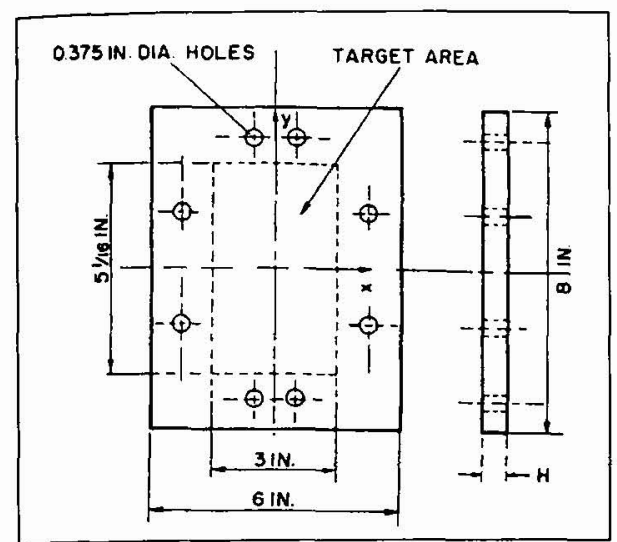

Fig. 1. Rectangular plate specimen [1]. (Dimensions in inches)

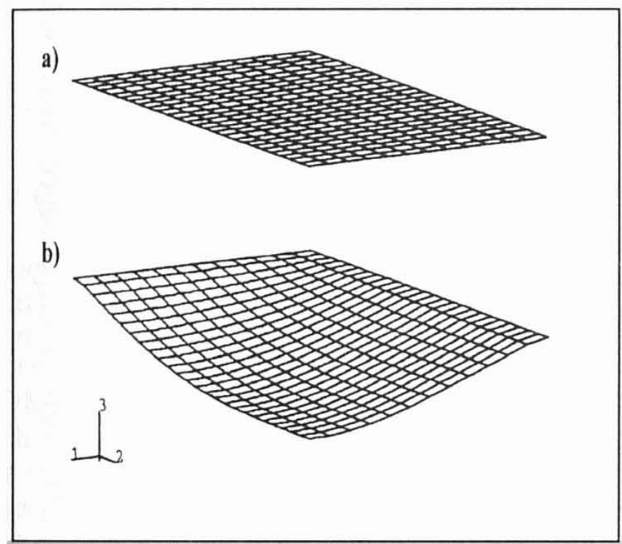

Fig. 3. a) udeformed mesh;

b) final deflection for steel specimen ( $\dot{w}_{0}=70 \mathrm{~m} / \mathrm{s}, \mathrm{H}=2.5 \mathrm{~mm}$ )

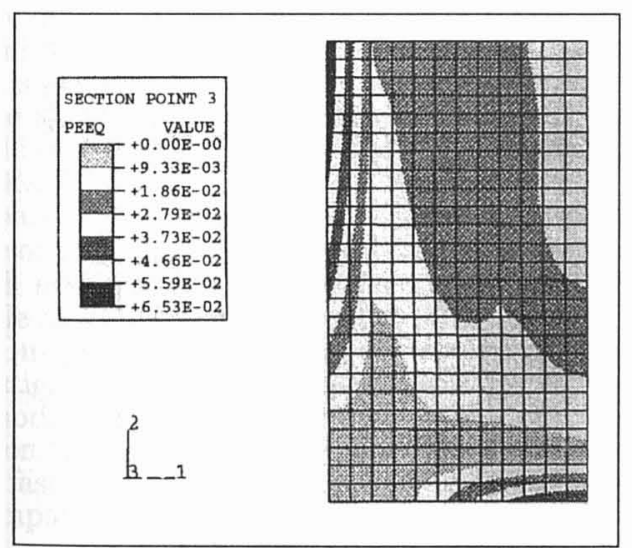

Fig. 5. Final distribution of eqivalent plastic strain in the midsurface of shell, $\left(\dot{\mathrm{w}}_{0}=70 \mathrm{~m} / \mathrm{s}, \mathrm{H}=2.5 \mathrm{~mm}\right)$

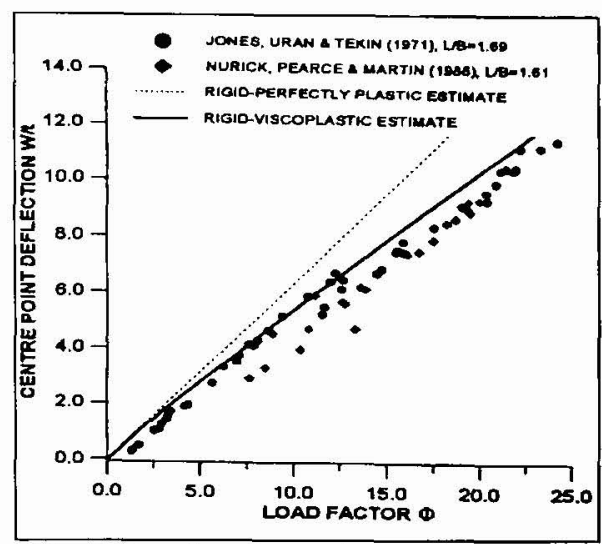

Fig. 2. Results of experiments [1], [6], and of simplified method.

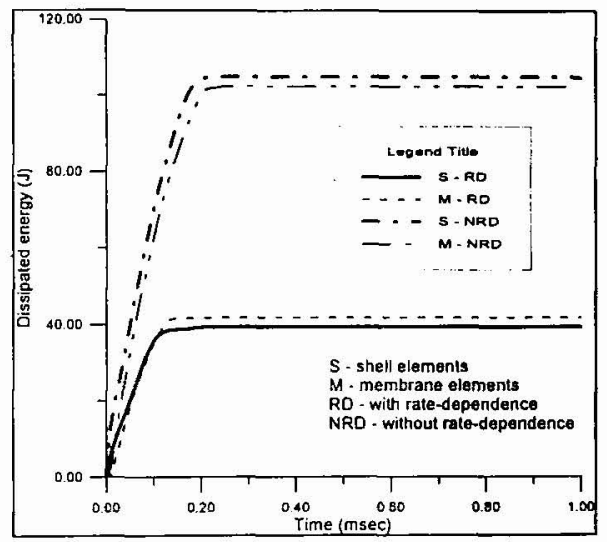

Fig. 4. Dissipated energy for various discrete models

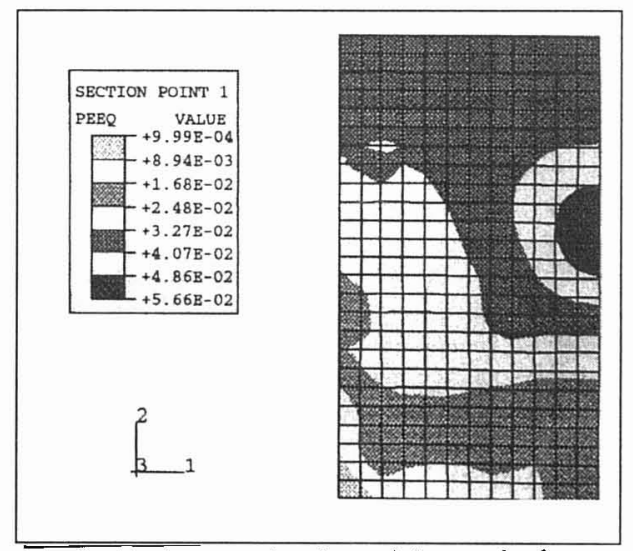

Fig. 6. Final distribution of the equivalent plastic strain in membrane,

$$
\left(\dot{\mathrm{w}}_{0}=70 \mathrm{~m} / \mathrm{s}, \mathrm{H}=2.5 \mathrm{~mm}\right)
$$



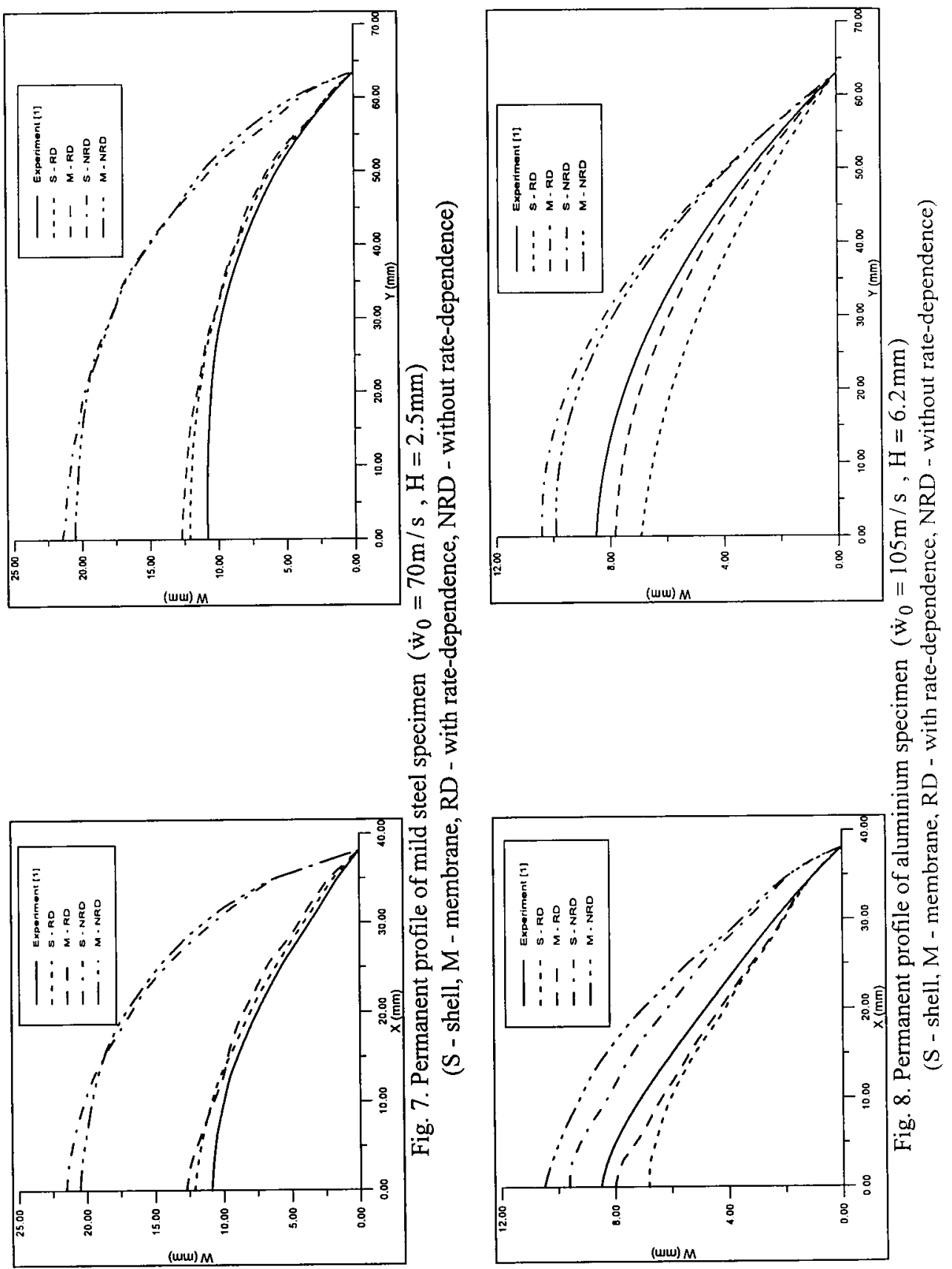